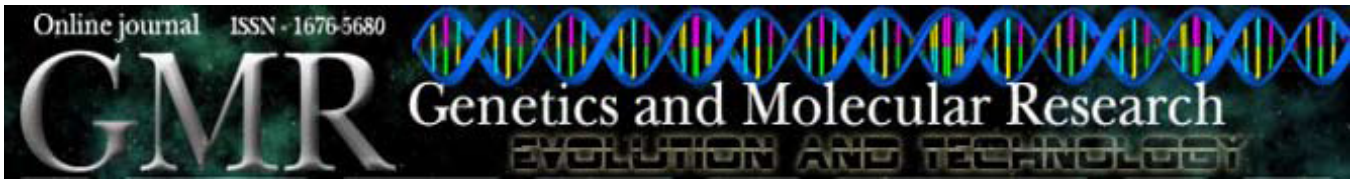

\title{
A novel polymorphism of the MYPN gene and its association with meat quality traits in Bos taurus
}

\author{
Y. Jiao ${ }^{1}$, L.S. Zan $^{1,2}$, Y.F. Liu ${ }^{1}$, H.B. Wang ${ }^{1,2}$ and B.L. Guo ${ }^{1}$ \\ ${ }^{1}$ College of Animal Science and Technology, \\ Northwest A\&F University, Yangling, Shaanxi, P.R. China \\ ${ }^{2}$ National Beef Cattle Improvement Center of Northwest A\&F University, \\ Yangling, Shaanxi, P.R. China \\ Corresponding author: L.S. Zan \\ E-mail: zanls@yahoo.com.cn
}

Genet. Mol. Res. 9 (3): 1751-1758 (2010)

Received May 6, 2010

Accepted July 19, 2010

Published August 31, 2010

DOI 10.4238/vol9-3gmr906

\begin{abstract}
Myopalladin (MYPN) is a multifunctional protein that maintains sarcomeric integrity and regulates Z-line structure. It is an important candidate gene for meat quality selection through markerassisted selection. Using PCR-RFLP technology, we discovered a singlenucleotide polymorphism (SNP) (A1795G in exon 9) of the MYPN gene. Allele frequencies of this SNP were investigated and evaluated by the $\chi^{2}$ test in 660 cattle populations in China; only the Nanyang population was not in Hardy-Weinberg equilibrium. Gene heterozygosity, effective allele number and polymorphism information content of the bovine MYPN locus in seven populations varied from 0.3888 to $0.4998,1.6360$ to 1.9992 , and 0.3132 to 0.3749 , respectively. We also looked for a potential association of this SNP with ultrasound traits in 399 individuals and found a significant effect on the ultrasound loin-muscle area. Meat quality traits were analyzed in another 61 Qinchuan individuals to analyze associations with genotype. Animals with the genotype GG had higher mean values for loin-eye area $(\mathrm{P}<0.05)$ and water-holding capacity $(\mathrm{P}<$ $0.01)$ than those with AA or AG genotypes. We conclude that this SNP of the MYPN gene has potential as a genetic marker for meat quality traits in cattle reproduction and breeding.
\end{abstract}

Key words: Cattle; MYPN gene; SNP; PCR-RFLP; Meat quality traits 


\section{INTRODUCTION}

The myopalladin (MYPN) gene belongs to a small gene family that also includes the Z-line proteins palladin and myotilin, all of which function as scaffolds that regulate actin organization (Silvia et al., 2008). Members of the palladin-myotilin-myopalladin family are important structural elements of the sarcomere Z-discs and characterized by conserved Ig-like domains (Salmikangas et al., 1999; Parast and Otey, 2000; Otey et al., 2005; Silvia et al., 2008). This particular type of Ig domain is a signature domain of this protein family and may play a special role in creating the highly ordered cytoskeleton of the sarcomere (Vaughan et al., 1992; Gilbert et al., 1999). MYPN encodes a novel $145-\mathrm{kD}$ protein and has multiple roles in Z-line and I-band protein assemblies (Bang et al., 2001; Ma and Wang, 2002; McElhinny et al., 2003). This protein is expressed in a restricted pattern and mainly exists in the Z-line of heart and skeletal muscle (Bang et al., 2001). On the one hand, MYPN tethers together nebulin and $\alpha$-actinin in vertebrate Z-lines (Ma and Wang, 2002; McElhinny et al., 2003), and $\alpha$-actinin binds directly to thin filaments and titin filaments (Ohtsuka et al., 1997; Sorimachi et al., 1997; Young et al., 1998). These interactions provide a mechanism for precisely tethering all known filament system in the Z-line. On the other hand, MYPN binds to cardiac ankyrin repeat protein (CARP), a nuclear transcription regulator involved in the control of muscle expression, in the central I-band of striated muscle sarcomeres (Bang et al., 2001; Mestroni, 2009). Overexpression of myopalladin's CARP-binding region could result in severe disruption of sarcomeric components. This result suggests that myofibrillar organization is linked to muscle gene expression, which may occur through myopalladin's interaction with CARP (Bang et al., 2001; Knoll et al., 2002).

To our knowledge, there is no reported information so far on the polymorphism of bovine MYPN gene. Based on the important roles of MYPN in maintaining the integrity of the sarcomere and regulating sarcomeric structure, MYPN could be an attractive candidate gene for meat quality traits in cattle. Therefore, the objective of this study was to detect singlenucleotide polymorphisms (SNPs) of the bovine MYPN gene and to explore their possible association with meat quality traits in Bos taurus.

\section{MATERIAL AND METHODS}

\section{DNA samples and data collection}

A total of 660 adult animals were randomly selected from breeding populations and used to analyze the MYPN allelic frequencies, including Qinchuan (QC, N = 333, Shanxi province), Nan yang ( $N Y, N=44$, Henan province), Jiaxian red (JR, $N=67$, Henan province), Xia'nan ( $\mathrm{XN}, \mathrm{N}=60$, Henan province), Luxi (LX, N = 52, Shandong province), Simmental and Luxi crossbred steers (SL, N = 51, Shandong province), and Xuelong ( $\mathrm{XL}, \mathrm{N}=53$, Liaoning province). Ultrasound measurements were available for 399 animals (Brethour, 1994; Hamlin et al., 1995), including ultrasound backfat thickness (UBF), ultrasound loin-muscle area (ULMA) and ultrasound marbling score (UMAR). Apart from that, 61 QC steers, 1.5 to 2 years old, were randomly selected and slaughtered to determine meat quality traits, including backfat thickness (BFT), loin- 
eye area (LEA), marbling score (MAR), water-holding capacity (WHC), and tenderness (TD). In order to minimize systematic error, a single person was assigned to measure one of the five meat quality traits in all animals.

Genomic DNA samples were obtained from the 660 animals. DNA samples were extracted from leukocytes and tissue samples using a standard phenol-chloroform protocol (Mullenbach et al., 1989).

\section{PCR amplification and sequencing}

According to the sequence of the bovine MYPN gene (GenBank accession No. NC_007329), one pair of primers (5'-CCTTTGGCTCATTTGGTCTGC-3' and 5'-ACTTGC TCATCTGCCACTCACC-3') was designed to amplify a 416-bp product of MYPN exon 9 and its intron region. Polymerase chain reaction (PCR) amplifications were performed in a $20-\mu \mathrm{L}$ reaction mixture containing $50 \mathrm{ng}$ DNA, $10 \mathrm{pM}$ of each primer, $0.20 \mathrm{mM}$ dNTP, $2.5 \mathrm{mM} \mathrm{MgCl} 2$ and $0.5 \mathrm{U}$ Taq DNA polymerase (TaKaRa, Dalian, China). PCR was performed using different DNA templates from the seven breeds. The cycling protocol was 5 min at $95^{\circ} \mathrm{C}$ and 32 cycles of denaturing at $94^{\circ} \mathrm{C}$ for $30 \mathrm{~s}$, annealing at $64^{\circ} \mathrm{C}$ for $30 \mathrm{~s}$ and extension at $72^{\circ} \mathrm{C}$ for $30 \mathrm{~s}$, followed by a final extension for $10 \mathrm{~min}$. The products for sequencing were purified with Axygen kits (MBI Fermentas, Canada) and sequenced in both directions in an ABI PRIZM 377 DNA sequencer (Perkin-Elmer, USA). The sequences were analyzed with the SeqMan software.

\section{Genotyping of MYPN allele by PCR-RFLP}

Aliquots of $20 \mu \mathrm{L}$ of the PCR products were digested with $10 \mathrm{U}$ Taq I (TaKaRa) at $65^{\circ} \mathrm{C}$ for $6 \mathrm{~h}$, following the supplier's manual. The digested products were detected by electrophoresis on a $1.5 \%$ agarose gel stained with ethidium bromide. To confirm the results based on the PCR-RFLP (restriction fragment length polymorphism) technique, the PCR products of different electrophoresis patterns were sequenced in both directions.

\section{Statistical analysis}

Based on the genotype number of the MYPN exon 9 and its flanking region locus in the breeds analyzed, the following items were statistically analyzed according to previous approaches (Nei and Roychoudhury, 1974; Nei and Li, 1979; Liu et al., 2010), including genotypic frequencies, allelic frequencies, Hardy-Weinberg equilibrium, gene homozygosity, effective allele numbers, and polymorphism information content (PIC). The association between SNP marker genotypes of the MYPN gene and records of ultrasound traits (UBF, ULMA and UMAR) was analyzed by the least-squares method as applied in the GLM procedure of SAS (SAS Institute Inc., Cary, NC, USA) according to the following statistical linear model:

$$
\mathrm{Y}_{\mathrm{ijkl}}=\mu+\mathrm{G}_{\mathrm{i}}+\mathrm{S}_{\mathrm{j}}+\mathrm{BF}_{\mathrm{k}}+\mathrm{Ma}_{1}+\varepsilon_{\mathrm{ijkl}}
$$

Meat quality traits (BFT, LEA, MAR, WHC, and TD) were also evaluated by comparing the genotypes of 61 Qinchuan individuals with respect to their phenotypic data by the least-squares method according to the following statistical linear model: 


$$
\mathrm{Y}_{\mathrm{ijkl}}=\mu+\mathrm{G}_{\mathrm{i}}+\mathrm{S}_{\mathrm{j}}+\mathrm{Ma}_{1}+\varepsilon_{\mathrm{ijkl}}
$$

where $\mathrm{Y}_{\mathrm{ijkl}}$ is observation for the meat quality traits, $\mu$ is overall mean for each trait, $\mathrm{G}_{\mathrm{i}}$ is genotype effect, $\mathrm{S}_{\mathrm{j}}$ is fixed effect of $\mathrm{sex}, \mathrm{BF}_{\mathrm{k}}$ is fixed effects of breed and farm, $\mathrm{Ma}_{1}$ is regression variable for measurement age, and $\varepsilon_{\mathrm{ijkl}}$ is random environment effect.

\section{RESULTS AND DISCUSSION}

After a 416-bp product of the MYPN gene was amplified and sequenced, we found an SNP, called A1795G, in the MYPN gene. It is a synonymous mutation of serine, which creates the Taq I restriction site $\left(\mathrm{T}^{\wedge} \mathrm{CGA}\right)$.

For the A1795G SNP in the seven populations analyzed, three size variants of restriction fragments were identified, namely 416, 265 and $151 \mathrm{bp}$. Subsequently, we analyzed the localization of migration bands of the restriction fragments and found three genotypes of "mutation A $>$ G". Figure 1 shows the following electrophoretic patterns: genotype AA represents the occurrence of one band of $416 \mathrm{bp}$; genotype AG represents three restriction fragment bands of 416, 265 and $151 \mathrm{bp}$, and genotype GG represents two restriction fragment bands of 265 and $151 \mathrm{bp}$. In order to better understand the detailed genetic variation within the Chinese cattle MYPN gene, the polymorphic DNA amplification fragments between exon 9 and its flanking region were sequenced and the sequence data corresponded to the polymorphic patterns. The sequencing tracing are shown in Figure 2.

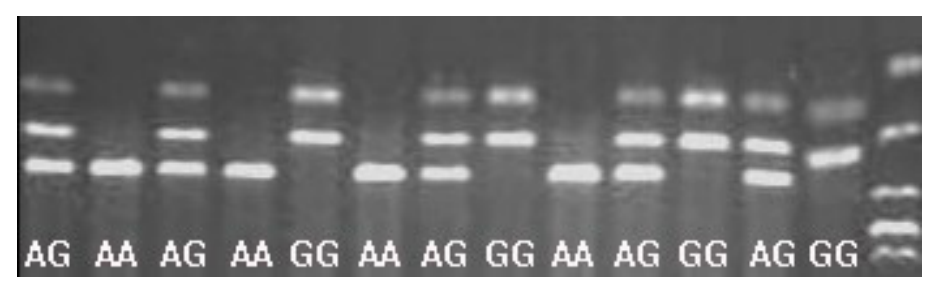

Figure 1. Agarose gel electrophoresis of Taq I PCR-RFLP. AA genotype shows one fragments (416 bp), AG genotype shows three fragments (416, 265 and $151 \mathrm{bp}$ ) and GG genotype shows two fragments (265 and $151 \mathrm{bp}$ ).
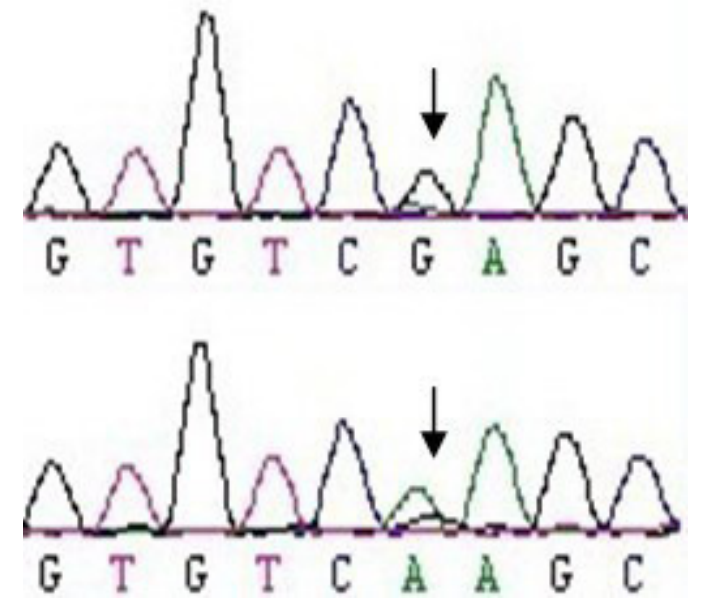

Figure 2. DNA sequencing tracing of exon 9 and its flanking region at the bovine MYPN locus. 
Moreover, allele frequencies of the SNP were determined and evaluated by the $\chi^{2}$ test in all Bos taurus populations in our study (Table 1). The data shown here demonstrate that the range of frequencies of MYPN-A allele was from 0.3977 to 0.7358 among seven different subpopulations of a Bos taurus population, and there was a significant difference in the allelic frequency between the QC and NY $(\mathrm{P}<0.05)$ populations, suggesting that $\mathrm{QC}$ and $\mathrm{NY}$ were not in Hardy-Weinberg equilibrium. The frequencies of the GG genotype were from 0.0631 in the QC population to 0.3137 in the SL population, which were relatively low in the seven populations (Table 1). This observation is possible because of the occurrence of random genetic drift due to the low frequency of the G allele.

\begin{tabular}{|c|c|c|c|c|c|c|c|c|}
\hline \multirow[t]{2}{*}{ Breed } & \multicolumn{3}{|c|}{ Observed genotypes $(\mathrm{N})$} & \multirow[t]{2}{*}{ Total } & \multicolumn{2}{|c|}{ Allelic frequencies } & \multirow[t]{2}{*}{$\chi^{2}(\mathrm{HW})$} & \multirow[t]{2}{*}{$\mathrm{P}(\mathrm{HW}$} \\
\hline & AA & $\mathrm{AG}$ & GG & & $\overline{\mathrm{A}}$ & G & & \\
\hline$\overline{\mathrm{QC}}$ & 0.4114 (137) & $0.5255(175)$ & $0.0631(21)$ & 333 & 0.6742 & 0.3258 & 12.82 & 0.0016 \\
\hline NY & $0.0455(2)$ & $0.7045(31)$ & $0.2500(11)$ & 44 & 0.3977 & 0.6023 & 9.75 & 0.0077 \\
\hline $\mathrm{JR}$ & $0.2985(20)$ & 0.6119 (41) & $0.0896(6)$ & 67 & 0.6045 & 0.3955 & 5.24 & 0.0727 \\
\hline XN & $0.2667(16)$ & $0.5333(32)$ & $0.2000(12)$ & 60 & 0.5333 & 0.4667 & 0.31 & 0.8581 \\
\hline LX & $0.2308(12)$ & $0.5000(26)$ & $0.2692(14)$ & 52 & 0.4808 & 0.5192 & 0.00 & 0.9999 \\
\hline $\mathrm{SL}$ & $0.2941(15)$ & $0.3922(20)$ & $0.3137(16)$ & 51 & 0.4902 & 0.5098 & 2.37 & 0.3064 \\
\hline $\mathrm{XL}$ & $0.5660(30)$ & $0.3396(18)$ & $0.0943(5)$ & 53 & 0.7358 & 0.2642 & 0.85 & 0.6549 \\
\hline Total & $0.3515(232)$ & $0.5197(343)$ & $0.1288(85)$ & 660 & 0.6114 & 0.3886 & 5.79 & 0.0554 \\
\hline
\end{tabular}

Gene heterozygosity, effective allele numbers and PIC of the bovine MYPN locus in seven populations of the Bos taurus breed varied from 0.3888 to $0.4998,1.6360$ to 1.9992 and 0.3132 to 0.3749 , respectively (Table 2 ). Gene homozygosity is higher than gene heterozygosity in all Bos taurus breeds studied. Generally, PIC is classified into the following three types: low polymorphism (PIC value $<0.25)$, intermediate polymorphism $(0.25<$ PIC value $<0.5)$ and high polymorphism (PIC value $>0.5$ ). According to this classification of PIC, all the Bos taurus population belongs to the intermediate polymorphism level, and there is no significant difference in PIC value between the seven breeds (Table 2).

\begin{tabular}{lcccc}
\multicolumn{4}{l}{ Table 2. Population genetic indices at the MYPN locus in cattle populations. } \\
\hline Breed & Gene homozygosity & Gene heterozygosity & Effective allele numbers & PIC \\
\hline QC & 0.5607 & 0.4393 & 1.7836 & 0.3428 \\
NY & 0.5209 & 0.4791 & 1.9197 & 0.3643 \\
JR & 0.5218 & 0.4782 & 1.9163 & 0.3638 \\
XN & 0.5022 & 0.4978 & 1.9912 & 0.3739 \\
LX & 0.5007 & 0.4993 & 1.9970 & 0.3746 \\
SL & 0.5002 & 0.4998 & 1.9992 & 0.3749 \\
XL & 0.6112 & 0.3888 & 1.6360 & 0.3132 \\
Total & 0.5248 & 0.4752 & 1.9055 & 0.3623 \\
\hline
\end{tabular}

$\mathrm{PIC}=$ polymorphism information content. For breed abbreviations, see legend to table 1 .

We then analyzed three ultrasound traits (UBF, ULMA and UMAR) by comparing the genotypes of 399 individuals of the seven populations studied with regard to their phenotypic data. The results of association analysis are shown in Table 3. At the SNP marker, there are significant effects on the ULMA $(\mathrm{P}<0.05)$, where animals with the genotype GG have higher mean 
ULMA values than those with genotypes AA and AG. Besides, we also analyzed the association between genotypes and meat quality traits, including BFT, LEA, MAR, WHC, and TD, in another $61 \mathrm{QC}$ individuals. The results are shown in Table 4, from which we can see that there are significant differences between the different genotypes for LEA $(\mathrm{P}<0.05)$ and WHC $(\mathrm{P}<$ 0.01 ). Animals with the GG genotype have higher mean values for LEA and WHC than those with the AG and GG genotypes, and the analysis of results for LEA in the 61 QC individuals coincides with the results of the ultrasound traits. No other significant correlation was observed between any of the marker genotypes at A1795G for the other traits. Moreover, the A>G synonymous mutation of serine results in the increase in part of the phenotypic variation, especially for LEA and WHC phenotypes in the animals studied. Therefore, we assume that the mutation for A1795G could have an important influence on many minor genes involved in LEA and WHC.

Table 3. Association between A1795G SNP genotypes of MYPN gene and ultrasound traits in Bos taurus.
\begin{tabular}{lccc}
\hline Genotype & Traits (mean \pm SE) \\
\cline { 2 - 4 } & $\mathrm{UBF}(\mathrm{mm})$ & $\mathrm{ULMA}\left(\mathrm{cm}^{2}\right)$ & $\mathrm{UMAR}$ \\
\hline AA & $0.365 \pm 0.01$ & $70.98 \pm 1.07^{\mathrm{a}}$ & $7.76 \pm 0.05$ \\
AG & $0.360 \pm 0.01$ & $73.78 \pm 0.95^{\mathrm{b}}$ & $7.71 \pm 0.04$ \\
GG & $0.360 \pm 0.01$ & $77.40 \pm 2.41^{\mathrm{b}}$ & $7.76 \pm 0.07$ \\
P & 0.8690 & 0.0119 & 0.6711 \\
\hline
\end{tabular}

Means with different superscript letters are significantly different $(\mathrm{P}<0.05) . \mathrm{UBF}=$ ultrasound backfat thickness; $\mathrm{ULMA}=$ ultrasound loin-muscle area; $\mathrm{UMAR}=$ ultrasound marbling score.

Table 4. Association between A1795G SNP genotypes of MYPN gene and ultrasound traits in QC cattle.

\begin{tabular}{lccccc}
\hline \multirow{2}{*}{ Genotype } & \multicolumn{4}{c}{ Traits (mean \pm SE) } \\
\cline { 2 - 6 } & BFT $(\mathrm{mm})$ & LEA $\left(\mathrm{cm}^{2}\right)$ & MAR & WHC & TD \\
\hline AA & $0.89 \pm 0.08$ & $81.33 \pm 0.10^{\mathrm{a}}$ & $2.17 \pm 0.15$ & $0.24 \pm 0.01^{\mathrm{A}}$ & $1.84 \pm 0.15$ \\
AG & $0.86 \pm 0.08$ & $76.88 \pm 0.38^{\mathrm{a}}$ & $2.34 \pm 0.16$ & $0.22 \pm 0.01^{\mathrm{A}}$ & $2.02 \pm 0.11$ \\
GG & $0.92 \pm 0.08$ & $89.44 \pm 1.22^{\mathrm{b}}$ & $2.00 \pm 0.18$ & $0.30 \pm 0.05^{\mathrm{B}}$ & $1.72 \pm 1.72$ \\
P & 0.9354 & 0.0156 & 0.6910 & 0.0010 & 0.5886 \\
\hline
\end{tabular}

Means with different superscript lower case letters are significantly different $(\mathrm{P}<0.05)$. Means with different superscript capital letters are significantly different $(\mathrm{P}<0.01)$. BFT $=$ backfat thickness; LEA $=$ loin-eye area; MAR $=$ marbling score $\mathrm{WHC}=$ water-holding capacity; $\mathrm{TD}=$ tenderness.

The meat quality traits of cattle are affected by many factors, such as genotype, sex, breed, herd, location, and other random environment factors. However, we established a new statistical model in which three factors (breed, herd and location) were involved, and we then employed the least-squares method in the GLM procedure of the SAS software to do the related analysis. However, we did not find any significant difference $(\mathrm{P}>0.05)$ (data not shown).

As we have pointed out, MYPN is an important sarcomere protein and has multiple roles in Z-line and I-band protein assemblies. Studies on polymorphisms of the MYPN gene have been conducted in both humans and pigs. In humans, four independent heterozygous mutations of the MYPN gene have been identified. Genetic studies, together with histological and functional evidence research, have suggested that MYPN could be involved in idiopathic dilated cardiomyopathy (Duboscq-Bidot et al., 2008). In pigs, an association analysis of functional candidate genes derived from gene-expression profiles of prenatal porcine muscle with meat quality and muscle 
deposition revealed that MYPN exhibited an association with ham weight and lean content (Wimmers et al., 2007). These results have been further confirmed by SNP studies of the MYPN gene (Davoli et al., 2003; Wang et al., 2007). Furthermore, a recent study has shown that two SNPs frequently occur in pigs and that the MYPN gene has a significant influence on BFT, LEA and intramuscular fat (Du et al., 2009). Above all, although many studies focus on MYPN gene variants, association studies in cattle and other livestock have never been reported. Therefore, based on these results of the genome-wide approach in porcine, considering the evolutionarily conservation between cattle and pig, we apply the research results of porcine MYPN to analyze polymorphism and genetic effects on cattle MYPN gene locus. The present study is the first to show that the A1795G SNP of bovine MYPN is significantly associated with loin-eye area and water-holding capacity (Tables 3 and 4 ) in cattle. These results are consistent with the findings reported in pigs.

In conclusion, we identified an SNP in the MYPN gene and investigated its relevance in seven Bos taurus populations. Our results provide evidence that the MYPN gene may have potential effects on meat quality traits in cattle. Therefore, further study will be necessary before using this SNP for marker-assisted selection in larger populations. It is also important to determine whether the MYPN gene plays a role in the development of those traits and whether it is involved in linkage disequilibrium with other causative mutations.

\section{ACKNOWLEDGMENTS}

Research supported by the China National 863 Program (\#2008AA1010 and \#2006AA10Z1A1), the National Eleventh "Five Year" Science and Technology Support Project (\#2006BAD01A10-3), and GMO new varieties major project (\#2008ZX08007-002). Moreover, the cattle populations were supported by the Qinchuan beef cattle breeding center of Shaanxi province, Nanyang, Jiaxian and Xianan cattle breeding center of Henan province, Luxi cattle breeding center of Shandong province, and Snow dragon beef cattle breeding center of Liaoning province (P.R. China).

\section{REFERENCES}

Bang ML, Mudry RE, McElhinny AS, Trombitas K, et al. (2001). Myopalladin, a novel 145-kilodalton sarcomeric protein with multiple roles in Z-disc and I-band protein assemblies. J. Cell Biol. 153: 413-427.

Brethour JR (1994). Estimating marbling score in live cattle from ultrasound images using pattern recognition and neural network procedures. J. Anim. Sci. 72: 1425-1432.

Davoli R, Braglia S, Lama B, Fontanesi L, et al. (2003). Mapping, identification of polymorphisms and analysis of allele frequencies in the porcine skeletal muscle myopalladin and titin genes. Cytogenet. Genome Res. 102: 152-156.

Du DS, Zhai LW, Xu DA and Wang CD (2009). SNPs detection of EPOR \& MYPN gene and association with meat quality traits in porcine. Acta Vet. Zootech. Sin. 36: 80-83.

Duboscq-Bidot L, Xu P, Charron P, Neyroud N, et al. (2008). Mutations in the Z-band protein myopalladin gene and idiopathic dilated cardiomyopathy. Cardiovasc. Res. 77: 118-125.

Gilbert R, Cohen JA, Pardo S, Basu A, et al. (1999). Identification of the A-band localization domain of myosin binding proteins C and H (MyBP-C, MyBP-H) in skeletal muscle. J. Cell. Sci. 112 (Pt 1): 69-79.

Hamlin KE, Green RD, Cundiff LV, Wheeler TL, et al. (1995). Real-time ultrasonic measurement of fat thickness and longissimus muscle area: II. Relationship between real-time ultrasound measures and carcass retail yield. J. Anim. Sci. 73: 1725-1734.

Knoll R, Hoshijima M and Chien KR (2002). Z-line proteins: implications for additional functions. Eur. Heart J. Suppl. 4: I-13-I-17.

Liu YF, Zan LS, Li K, Zhao SP, et al. (2010). A novel polymorphism of GDF5 gene and its association with body measurement traits in Bos taurus and Bos indicus breeds. Mol. Biol. Rep. 37: 429-434. 
Ma K and Wang K (2002). Interaction of nebulin SH3 domain with titin PEVK and myopalladin: implications for the signaling and assembly role of titin and nebulin. FEBS Lett. 532: 273-278.

McElhinny AS, Schwach C, Valichnac M, Mount-Patrick S, et al. (2003). Nebulin: the nebulous, multifunctional giant of striated muscle. Trends Cardiovasc. Med. 13: 195-201.

Mestroni L (2009). Phenotypic heterogeneity of sarcomeric gene mutations: a matter of gain and loss? J. Am. Coll. Cardiol. 54: 343-345.

Mullenbach R, Lagoda PJ and Welter C (1989). An efficient salt-chloroform extraction of DNA from blood and tissues. Trends Genet. 5: 391.

Nei M and Roychoudhury AK (1974). Sampling variances of heterozygosity and genetic distance. Genetics 76: 379-390.

Nei M and Li WH (1979). Mathematical model for studying genetic variation in terms of restriction endonucleases. Proc. Natl. Acad. Sci. U.S.A. 76: 5269-5273.

Ohtsuka H, Yajima H, Maruyama K and Kimura S (1997). Binding of the N-terminal $63 \mathrm{kDa}$ portion of connectin/titin to alpha-actinin as revealed by the yeast two-hybrid system. FEBS Lett. 401: 65-67.

Otey CA, Rachlin A, Moza M, Arneman D, et al. (2005). The palladin/myotilin/myopalladin family of actin-associated scaffolds. Int. Rev. Cytol. 246: 31-58.

Parast MM and Otey CA (2000). Characterization of palladin, a novel protein localized to stress fibers and cell adhesions. J. Cell. Biol. 150: 643-656.

Salmikangas P, Mykkanen OM, Gronholm M, Heiska L, et al. (1999). Myotilin, a novel sarcomeric protein with two Iglike domains, is encoded by a candidate gene for limb-girdle muscular dystrophy. Hum. Mol. Genet. 8: 1329-1336.

Silvia MG, Daniel A and Carol AO (2008). The role of palladin in actin organization and cell motility. Cell Biol. 87: 517-525.

Sorimachi H, Freiburg A, Kolmerer B, Ishiura S, et al. (1997). Tissue-specific expression and alpha-actinin binding properties of the Z-disc titin: implications for the nature of vertebrate Z-discs. J. Mol. Biol. 270: 688-695.

Vaughan KT, Weber FE and Fischman DA (1992). cDNA cloning and sequence comparisons of human and chicken muscle C-protein and 86 kD protein. Symp. Soc. Exp. Biol. 46: 167-177.

Wang C, Huang ZH and Zhang XQ (2007). Analysis on associations of myopalladin gene polymorphisms with carcass traits in pigs. Acta Vet. Zootech. Sin. 38: 760-764.

Wimmers K, Murani E, Te Pas MF, Chang KC, et al. (2007). Associations of functional candidate genes derived from gene-expression profiles of prenatal porcine muscle tissue with meat quality and muscle deposition. Anim. Genet. 38: 474-484.

Young P, Ferguson C, Banuelos S and Gautel M (1998). Molecular structure of the sarcomeric Z-disk: two types of titin interactions lead to an asymmetrical sorting of alpha-actinin. EMBO J. 17: 1614-1624. 